\title{
Health Scope
}

\section{Combined Effect of Noise and Chemical Substances on Hearing: What is Known and Future Research Needs.}

\author{
Ramazan Mirzaei ${ }^{1}$, Alireza Ansari-Moghaddam ${ }^{1, *}$ \\ ${ }^{1}$ Health Promotion Research Center, Zahedan University of Medical Sciences (ZUMS), Zahedan, IR Iran \\ * Corresponding author: Alireza Ansari-Moghaddam, Health Promotion Research Center, Zahedan University of Medical Sciences (ZUMS), Zahedan, IR Iran. \\ Tel: +98-9155412155, Fax: +98-5412419403, E-mail: ansarialireza@yahoo.com.
}

Keywords: Noise; Databases, Chemical; Substance, Hearing Loss

Noise induced hearing loss (NIHL) is one of the most prominent occupational diseases in all regions of the world which could be caused by exposure to loud sounds or noise at a work in wide spectrum of industries. Globally, it is accounting for $16 \%$ of the disabling hearing loss in adults (over 4 million DALYs) with a range of $7 \%$ to $21 \%$ in the differentsubregions $(1,2)$. It has been estimated that more than 30 million workers in the United States of America and around 30 millions of people in European courtiers are exposed to loud sounds (defined as hazardous by WHO) which might result in hearing loss(3). Occupations at highest risk for NIHL include firemen, armed police, police motorcyclists, soldiers, construction and factory workers, printers, foundry workers, musicians, farmers, lorry drivers and miners. Noise is considered one of the most pervasive and harmful agents in crowded cities as well. In a study conducted in South Eastern city of Iran-Zahedan, approximately more than $80 \%$ of the studied subjects ranked noise pollution too high at streets(4). Importantly, noise is no longer noticeable as the only source of work-related hearing loss and more attention is essential to the matter of joint risks for workers exposed to hazardous noise with work-related substances. Most threshold limit values are established for a single chemical substance and a single physical agent(5). However, the work environment is often composed of multiple chemical agent exampletoluene, styrene and benzene exposures and physical exposure such as noise, vibration and other stress.

There is some evidence that employees exposed to the chemical substances suffered significantly from hearing impairment whereas noise levels were considerably lower than their corresponding individuals. The harmful effect of a chemical substance on ear function was first described by the Persian philosopher Avicenna (Abu Ali alHusaynibnAbd-AllahibnSinaBalkhi). He notified in his Canon of Medicine that using mercury vapor for treatment of head lice could causedeafness in patients(6). Accordingly, workers at the abovementioned occupations might be possibly exposed to multiple agents simultaneously.

Article type: Editorial; Received: 06 Feb 2013, Revised: 08 Feb 2013, Accepted: 09 Feb 2013

-Implication for health policy/practice/research/medical education:

This manuscript explained the joint effects of hazardous noise with work-related chemical substances on hearing. Reading this article is recommended to the specialists in the field of occupational and environmental health, industrial management and health policy makers.

Please cite this paper as:

Mirzaei R, Ansari-Moghaddam A. Combined Effect of Noise and Chemical Substances on Hearing: What is Known and Future Research Needs. Health Scope. 2012; 1 (4):155-157. DOI: 10.17795/jhealthscope-10590

Copyright (c) 2014, Health Promotion Research Center. This is an open-access article distributed under the terms of the Creative Commons Attribution License, which permits unrestricted use, distribution, and reproduction in any medium, provided the original work is properly cited. 
Interactions can occur in a variety of ways and by a number of mechanisms such as alterations in absorption, biotransformation and protein binding. The response of the organism to combinations of toxicants may be also increased or decreased because of the toxicological responses at the site of action. The effects of two chemicals can be additive when combined effect of two chemicals is equal to the sum of the effect of each agent (i.e. $2+3$ equal 5), synergistic effect is the situation in which the combined effect of two chemicals is much greater than the sum of the effect of each agent given alone (i.e. $2+2$ equal 20) and potentiation in which one substance does not have a toxic effect on a certain organ or system, but it makes the later much more toxic (i.e. $0+2=10$ ) in addition to antagonistic effects are often very desirable effects in toxicology and are the basis of many antidotes $(7,8)$.

For example, the combined effect of noise and chemicals, particularly noise and solvents such as toluene, styrene, xylene, trichloroethylene and their mixture on hearing have been demonstrated in numerous animal experiments. Therefore, the hazardous effect of noise exposure as a well-established cause of hearing loss could be aggravated by harmfuleffectsof other agents such chemical substances. Furthermore, the balance and auditory central nervous system function might be also affected by solvent such that it is not expected from noise exposure alone. Similarly, NIHL has been found to be potentiated by some of air pollutants such as carbon monoxide(9-12). In a study conducted on two groups of rabbits (one group exposed to noise and the second one exposed to noise plus carbon monoxide (CO); The noise group had a $44.9 \mathrm{~dB}$ threshold loss on 8th day and 20.3 $\mathrm{dB}$ threshold loss on 22nd day averaged across frequencies of 1-8 KHz, while animals receiving noise plus $\mathrm{CO}$ had a $58.4 \mathrm{~dB}$ and $27.8 \mathrm{~dB}$ average thresholdloss on 8 th and 22nd days, respectively(2). Accordingly, the discrepancy on the prevalence and degree of NIHL within a group and among groups might be partly explained by the toxic effects of industrial chemicals and their interaction with noise on auditory system.

Nevertheless, there is insufficient scientific knowledge and understanding of the risks of combined exposures, as most of conducted studies have mainly focused on single factors and mainly on animals. Moreover, the majority of these studies had a cross-sectional design which might not be adequate for interpretation of the causation relationship. There is also limited data on dose-response relationship of noise alone and along with chemical substances on hearing. Above all, developed occupational safety criteria is currently based on isolated workplace hazardous that is not adequate for protecting workers who may be exposed with multiple harmful agents at their workplace coincidently and sequentially.

Therefore, well-designed cohort studies are needed to evaluate the impact of noise and work-related ototoxic substance exposure in humans. Besides, standards hearing conservation practices should take the increased risk of combined exposure to noise and chemical substances into consideration. Medical surveillance should be also considered for workers co-exposed to noise and ototoxic substances frequently, irrespective of the noise exposure level. Additionally, health results of workers should be recorded and checked regularly in order to detect early changes at individual and collective levels. It is also of utmost importance to educate and motivate the relevant stakeholders in hearing conservation programmers including exposure to chemicals.

\section{Acknowledgements}

None declared.

\section{Authors' Contribution}

This study has been done equally by authors.

\section{Financial Disclosure}

None declared.

\section{Funding/Support}

None declared.

\section{References}

1. Nelson DI, Nelson RY, Concha-Barrientos M, Fingerhut M. The global burden of occupational noise-induced hearing loss. Am J Ind Med.2005;48(6):446-58.

2. Motallebi Kashani M, Mortazav SB, Khavanin A, Allameh A, Mirzaee A, Akbari M. Protective Effects of $\alpha$-Tocopherol on ABR Threshold Shift in Rabbits Exposed to Noise and Carbon Monoxide. Iran JPharma Res.2011;10(2):339-346.

3. Combined exposure to Noise and Ototoxic Substances. EU-OSHA - European Agency for Safety and Health at Work. 4. 6.3. p.

4. Mirzaei R, Ansari-Moghaddam A, Mohammadi M, Rakhshani F, Salmanpor M. Noise pollution in Zahedan and residents knowledge about noise pollution.J Health Scope.2012;1(1):3-6.

5. American Conference Governmental Industrial Health (ACGIH). Threshold limit values for chemical substance, physical agents and biological exposure indicies. 2011; p.

6. Proceedings of the International Workshop , . Synergistic exposure to noise, vibrations and ototoxic substances. 2010; $p$

7. Amdur M, Doull J, Klaassen CD. Toxicology the basic science of poisons.1992; p.

8. Williams P, James RC, Roberts SM. Principles of toxicology Environ mental and Industrial Applications.2000;23.

9. Fechter LD, Young JS, Carlisle L. Potentiation of noise induced threshold shift and hair cell loss by carbonmonoxide. Hear Res.1988;34(1):39-47.

10. Young JS, Upchruch MB, Kaufman MJ, Fechter LD. Carbon monoxide exposure potentiates high-frequency threshold shifts induced by noise. Hear Res.1987;26(1):37-43.

11. Chen GD, Kong J, Reinhard K, Fechter LD. NMDA receptor block age protects against permanent noiseinducedhearing loss but not its potentiation by carbon monoxide. Hear Res.2001;154(12):108-15.

12. Chen GD, McWilliams ML, Fechter LD. Intermittent noise in duced hearing loss and the influence ofcarbon monoxide. Hear Res.1999;138(1-2):181-91. 